\title{
Acceptability of an adventure video game in the treatment of female adolescents with symptoms of depression
}

\author{
Álvaro E. Carrasco \\ Faculty of Medicine, University of Chile, Santiago, Chile
}

\begin{abstract}
While many adolescent patients resistantly engage in psychotherapy, they are attracted by new technologies and video games. A development and research project was implemented to design an online adventure video game as a psychotherapeutic tool for depressed adolescents and to evaluate its acceptability. The game design followed the narrative structure of the hero's journey and ideas from the cognitive behavioral and interpersonal psychotherapy models for depression. Five psychotherapists and fifteen of their female adolescent patients with symptoms of depression tested the game. Some patients valued the video game in terms of learning helpful social and mental health-related behaviors. Therapists manifested that a video game like Maya could be a useful complementary tool for psychotherapy of adolescent girls. The study suggests that future developments of video games for mental health are worthwhile and it provides some ideas on how to incorporate psychotherapeutic notions in ludic environments.
\end{abstract}

Key words: Psychotherapy research; Adolescent psychotherapy; Video games; Depression.

Correspondence: Alvaro Carrasco, Millennium Institute for Research on Depression and Personality, Pontificia Universidad Católica de Chile, Avda. Vicuña Mackenna 4860 (Campus San Joaquín), MIDE-UC of. 202, 2nd floor Macul, Santiago, Chile. Tel: +56.975598982 .

E-mail: athos@med.uchile.cl

Acknowledgments: this article is based on the author's doctoral dissertation. This research was supported in part by grants from Chile's National Commission for Scientific and Technological Research (CONICYT) and from the Fund for Innovation and Competitiveness (FIC) of the Chilean Ministry of Economy, Development and Tourism, through the Millennium Scientific Initiative, Grant IS130005. The author is particularly grateful for the advice and support provided by Doctor Juan Pablo Jiménez (Universidad de Chile), Doctor Hans Kordy (Center for Psychotherapy Research, Heidelberg University Hospital), Doctor Mariane Krause (Pontificia Universidad Católica de Chile) and Doctor Benjamin Zimmer (Center for Psychotherapy Research, Heidelberg University Hospital) during the development of the research. The author is especially grateful to the psychotherapists and young patients that contributed to this study.

Citation: Carrasco, Á.E. (2016). Acceptability of an adventure video game in the treatment of female adolescents with symptoms of depression. Research in Psychotherapy: Psychopathology, Process and Outcome, 19(1):10-18. doi: 10.4081/ripppo.2016.182

Received for publication: 13 July 2015.

Revision received: 23 February 2016.

Accepted for publication: 26 February 2016.

This work is licensed under a Creative Commons Attribution NonCommercial 4.0 License (CC BY-NC 4.0).

CCopyright Á.E. Carrasco, 2016

Licensee PAGEPress, Italy

Research in Psychotherapy:

Psychopathology, Process and Outcome 2016; 19:10-18

doi:10.4081/ripppo.2016.182

\section{Introduction}

It is known that many adolescents that suffer from psychological disorders do not seek help (Newman, 1996; Seeley, Stice, \& Rohde, 2009) and when they do, many of them have difficulties to engage with the psychotherapeutic process (Coyle, Doherthy \& Sharry, 2009). This happens because adolescents feel that their problems are too personal to talk about, that nobody can help them, or that they are able to cope with the situation by themselves (Coyle, Matthews, Sharry, Nisbet, \& Doherty, 2005). Frequently, therapy is imposed on young people, and they view the therapist as an authority figure. Also, there is still a social stigma attached to therapy that indisposes many adolescents.

Play has been a strategy commonly used, especially with children, to help patients express themselves. However, many forms of ludo-therapy that work well with children seem childish to adolescents, and they may refuse to engage in these forms of therapy. Nowadays, technology is the new mean of expression for teenagers, who are attracted to technological devices and feel comfortable using them.

Over the last few decades, there have been several initiatives to design and utilize video games for educational purposes and as psychotherapeutic tools for children and adolescents with diverse psychopathological conditions (Wilkinson, Ang, \& Goh, 2008). Promoters of the use of video games for learning and psychotherapy argue that: video games can contribute to establish the therapeutic relationship; video games can provide stimuli for therapeutic conversation; they can help to generate opportunities for the expression of unconscious aspects; in some contexts, the use of video games can provide diagnostic information; some video games have incorporated 
psychoeducational content, have integrated elements to model behavior and opportunities to exercise social problem resolution (Ceranoglu, 2010).

In the following pages, this article first briefly presents previous research about video games for psychotherapy and a general description of psychotherapies for depression, then the research questions are presented; it follows the methodological description of the research, the results and finally some main conclusions are outlined.

\section{Video games for psychotherapy}

During two decades, researchers have been studying the potential of video games for health, in psychological development, for education and psychotherapy (Wilkinson et al., 2008).

McFarlane, Sparrowhawk and Heald (2002) and Rebetez \& Betrancourt (2007) distinguish two potential uses of video games in learning environments: to provide scenarios to exercise cognitive and social abilities and to carry out content derived from instructional objectives. Ritter, Göbel and Steinmetz (2010) appreciate the potential of videogames and interactive stories to foster sensibility on social aspects. The basic idea is to integrate - in a subtle way - the topics in ludic environments of exploration, based on a narrative, with the purpose of increasing intrinsic motivation in order to deal with the topic at hand.

The use of video games in the area of general health has included psychoeducation on the management of chronic illnesses (e.g., diabetes and asthma) to improve adherence to treatment; video games as tools in physical treatment and rehabilitation after a brain injury; and, video games as a distraction from pain (Ceranoglu, 2010; Kato, 2010).

Baranowski, Buday, Thompson, and Baranowski (2008) mention that the use of electronic games for health purposes is in its developing stages, but the incorporation of procedures of behavioral change based on theory provide a reason to believe that they can be effective. Baranowski et al. (2008) carried out a literature review regarding this topic and they found that games for health led to desirable results, such as increase in knowledge, attitudinal and behavioral change. These researchers point out two methods through which video games can influence behavior. The first involves the incorporation of procedures regarding behavioral change (e.g. definition of goals) in the process of playing the game. The second involves the incorporation of concepts of behavioral change in the game narrative.

Some video games have been specifically designed for mental health purposes. There is evidence that video games are useful to deliver manualized interventions as the ones proposed by cognitive behavioral therapy (Ceranoglu, 2010). Video games have been used in the mental health field for: prevention of aggression, anxiety disorders and phobia (virtual reality), attention deficit, personality disorders, psychotic disorder, prevention of drug use, Asperger syndrome, autism and emotional support for hospitalized children (Wilkinson et al., 2008). Two examples of video games specifically designed as psychotherapeutic aid are Treasure Hunt (Brezinka, 2008) and Personal Investigator (Coyle et al., 2009). Results of research on these games are positive and present a promising view for digital ludic interventions for the prevention and treatment of psychological disorders (Wilkinson et al., 2008; Griffiths, 2003; Brezinka, 2008; Coyle et al., 2009). These games, though without doubt innovations of great value for the child and adolescent psychotherapy, did not take advantage of the potential of the narrative aspect present in adventure video games.

Adventure games are video games in which the player takes the role of the protagonist in an interactive story that is motivated by exploration, manipulation of objects, and/or the exchange of information between the characters that allows the resolution of puzzles or problems (Fernández-Vara \& Osterweil, 2010). The direct participation in a story and the adoption of a first person perspective in control of the events unfolding, are central aspects of interaction in adventure videogames. Players learn through planning, decision making, and by observing relationships of cause and effect. The game designer can structure the interactive options to afford significant feedback in terms of the player's decisions. The narrative offers possibilities for the divulgence of information and behavioral modeling. Due to these characteristics, it is estimated that this game genre can allow the incorporation of psychotherapeutic elements relevant for the treatment of depression.

\section{Treatment models of depression}

There is abundant evidence of the efficacy of cognitive-behavioral and interpersonal treatments for depression. Also, evidence exists regarding change due to psychoanalytically oriented psychotherapies (Vitiello, 2009; Moras, 2006; Roth \& Fonagy, 2005; Gladstone \& Beardslee, 2009).

Cognitive-behavioral theory attributes depression to cognitive distortions and its effect on social behavior and/or on alterations in the behavioral reinforcement patterns (Brewin, 1996; Davidson, Rieckmann, \& Lespérance, 2004). Interventions seek to modify cognitions and promote functional tools to cope with stress and improve interpersonal relationships (Horowitz \& Garber, 2006).

Interventions that follow the interpersonal model emphasize the identification of current interpersonal difficulties and stimulate strategies to face these difficulties. Therapy is centered on current relationship problems, helping the patient to identify dysfunctional patterns and stimulating, through the therapeutic relationship, the capacity to reflect on one and others (Hollon, Thase, \& Markowitz, 2002).

In synthesis, is common that interventions for depression focus on the present situation, particularly gearing attention towards the identification of relational patterns and dysfunctional cognitive styles. The interventions 
stimulate the process of recognition and reflection of the patient's own mental state and others, and its relationship to behavior and the consequences over affect and mood. Interventions that promote a real and positive perception of oneself are frequent. Behavioral activation is stimulated, as well as personal strategies to face problems, looking for healthy alternatives for problem-solving and reviewing social skills. All these strategies are not just promoted for overcoming a current state of depression; they also seek to be available in future situations that could trigger the recurrence of depressive symptoms.

\section{Research premise, aim and questions}

Risks related with the excessive use of technology and video games are frequently mentioned in the media and those risks and addictive behaviors concern the scientific community. This study, while recognizing the hazards of excessive technology use, follows a line of research that focuses on the potential benefits of play on digital devices.

The premise for this study is that adventure video games are mediums in which information, situations and activities relevant for psychotherapeutic purposes can be embedded. Given the lack of previous attempts to develop a video game of these characteristics, this study was designed to provide initial evidence of the therapeutic potential and to evaluate the acceptability by patients of an adventure video game for depressive patients. Depending on the results of this exploration, further developments of this methodology and more detailed studies may be justified.

The research questions that guided this study were: i) Is an adventure video game oriented towards the treatment of depression acceptable as a psychotherapeutic complementary tool by adolescent women? ii) Can an adventure video game oriented towards the treatment of depression in adolescent women contribute to focus psychotherapeutic interactions on patients' life aspects that are relevant for the treatment?

\section{Methods}

\section{Maya: an adventure video game as a tool in psychotherapy}

A web page was created to host the video game; to create a private online environment for patients and therapists that participated in the research; to deliver complementary information about depression and self-care recommendations (the Mind your mind section); to log the players' activities; and to deploy instruments of evaluation. It could be said that the web platform and the game were integrated in an online game system.

Three focus groups in two schools were conducted with girls between 14 and 18 years old as part of the video game design process. The overall objective of these activities was to obtain information for a user centered video game design. During these focus groups some girls men- tioned that they would prefer a narrative that would not address directly the typical adolescent situations: it would be boring to see your own life portrayed in a videogame, one of the girls said. Other girls suggested that the story should present situations in a metaphorical way: the problems should appear but in a kind of metaphor. These ideas influenced the writing of the game story.

The creation of the story followed the narrative structure of the hero's journey as originally stated by Campbell (1973) and later adapted by Vogler (2007). The hero path is a metaphor or a symbol of the process of human development (Jung, 1993) present in different cultures and it has served a pedagogical function (Campbell, 1991). The hero's journey model is commonly used in movies and in commercial videogames (Ip, 2010). Dickey (2006) and Delmas, Champagnat, and Augeraud's (2007) propose that the narrative structure of the hero's journey can be adapted to the design of interactive ludic learning environments.

Aspects of the cognitive behavioral and interpersonal psychotherapy models for depression guided the video game design. Three objectives were considered in the design of the narrative and the game interaction: recognition and modification of negative cognitive bias; promotion of interpersonal skills and interpersonal problem solving; behavioral activation and healthy living. These aspects were included in four ways: as decisions that the player had to take as the story unfolded; as a scoring system that tracked and provided immediate feedback cues about the three areas; as a post-game feedback text; and, as an information text in the Mind your mind section of the hosting website. In overall terms, players had to navigate and make decisions to move forward in the game story.

Based in part in the previous ideas, an interactive story was written; the story presented interpersonal situations that required psycho-social reasoning and that allowed the integration of theoretically relevant elements.

In the following paragraph a condensed version of the story of the video game Maya is presented.

Maya was an average teenager but she was feeling a little sad. During a walk in a park where she uses to go, she meets Izel, a girl about her age. Izel is a vivacious girl and after a small talk, Izel invites Maya to participate in an ecological movement and to go to a protest to stop the destruction of the park. Maya realizes that the day of the protest she has an exam at her school, so she goes to talk to her teacher, who denies the permit to go. Maya must ask another teacher to intercede to obtain authorization. She goes to the protest and unexpectedly she runs into her father, a lawyer who is representing the ecological movement. Then the story shows Izel who has information that could stop the destruction of the park. Izel asks Maya if she has a camera and that if she dares to take a risk helping her. Both girls go to photograph a government bureaucrat taking a bribe from an employee of the company that wants to destroy the park to build an industry. The girls 
are discovered so they flee with the evidence that later Maya passes to her father and that, in the end, it helps him to win the case and to save the park.

The score system provided cues about positive game behavior in the areas of Recognition and modification of negative cognitive bias, Interpersonal skills and interpersonal problem solving and Behavioral activation and a healthy lifestyle. This form of immediate feedback was presented by means of: i) an audio sound; ii) an increase in the percentage value next to the icon that represented the three areas already mentioned. No especial instructions on how to obtain a higher score were given to the players; this decision was made considering that providing explicit information about the positive behaviors could cause oppositional attitudes that affected the spontaneous play and the game experience. Thereby the score system just gave hints and a more explicit feedback was left to the end of the game. Immediately after ending the game, each player had a personalized feedback based on her decisions. The feedback reinforced positive behavior, presented questions for self-reflection and provided information related with the three areas of interest.

It was considered that the design of the video game had to be observed and approved by psychotherapists not involved in the planning and conduction of the study. Two psychotherapists collaborated, from the beginning, in the video game design process; it can be said that the final game and web page contents were influenced and sanctioned by these psychotherapists. In some specific moments, other two psychotherapists provided comments on the development of the game. These four therapists were different of the psychotherapists who consented to use the video game with their patients. In addition, the design of the video game online system received important contributions from the team at the Heidelberg Center for Psychotherapy Research.

\section{Subjects}

Several psychotherapists and health centers were contacted soliciting collaboration with the study. Two psychotherapists in private practice and three psychotherapists working in two public health institutions in Santiago of Chile consented to participate and provided cases to the study. One of the therapist had a master degree in clinical psychology, two had a master degree in children and adolescent clinical psychology, one had a post-graduate specialization diploma in child and adolescent clinical psychology and one was a psychologist with five years of clinical experience and several specialization clinical studies.

Based on a study protocol handed over by the researcher, the psychotherapists selected patients, invited them to participate and asked parents for their consent. The inclusion criteria were: female patients between 12 and 18 years old that had symptoms of depression or a diagnostic of mild or moderate depression. The exclusion criteria were: severe depression, current suicidal ideation, psychosis or intellectual disability.

According to the clinical evaluation of the psychotherapists, all the patients that were part of the study had symptoms of depression, mild or moderate depression. Patients that met the criteria, who accepted the invitation and whose parents also expressed their consent were given access to the video game.

The decision of when to invite patients to play the video game was left to the therapists' clinical judgment. Patients were invited in different stages of the psychotherapeutic process.

Fifteen patients, girls between 12 and 18 years old, consented to participate and played the game. The decision to focus the research in female patients was based in the recognition of the higher prevalence of depression in adolescent and adult women compared to men.

\section{Instruments}

\section{Acceptability scale}

Due to the innovative character of the project it was important to evaluate if patients accepted the video game as a complementary tool for psychotherapy. According to Kazdin (1980), acceptability refers to the judgments about the treatment procedures by nonprofessionals, lay persons, clients, and other potential consumers of treatment. One important reason to evaluate acceptability is that a treatment, even when efficacious, might not be accepted because of its intrusiveness and adverse secondary effects (Wolf, 1978). Treatments more accepted by patients are more likely to be sought out, initiated and adhered to (Kazdin, 1980).

Clinical research methodology in treatment acceptability has involved having clients rate treatment acceptability prior to, during, and/or after implementation of a treatment (Carter, 2007). Instruments to research acceptability have often relied on Likert rating scales that include items regarding specific treatment procedures (Carter, 2007).

While developing a specific questionnaire for this study, instruments to evaluate the acceptability of educational games were considered (Carter, 2007; Batista, \& Cornachione, 2005; Rovai, 2009; De Grove, Van Looy, \& Courtois, 2010). A preliminary version of the acceptability scale was developed and tested in a non-clinical sample $(n=147)$. As part of this process people were invited - via e-mail, social networks and video game forums - to play the online adventure video game The Quest for the Rest (Amanita Design, 2007), and then to respond the questionnaire.

The acceptability scale was finally composed by seven items; each item is a phrase that expresses an opinion about the value and benefit derived from playing the game. Players are asked to express their level of agreement for each phrase by choosing one of five possible answers (Nothing; Slightly; Moderately; A lot; Extremely) (Table 1).

The scale showed good psychometric qualities in terms 
of reliability and construct validity, highlighting a 1 factor model that explained $69.43 \%$ of the total item variance. Internal consistency was examined: Cronbach's alpha $=0.94$.

\section{Therapist interview guide}

A set of questions was prepared to guide the interviews of psychotherapists. The questions asked: if it was possible to review the video game during the sessions and, if so, what happened; the opinions of the therapists about the potential of a game like this as a complementary tool in psychotherapy and as a tool for preventive interventions on depression and mental health (Figure 1).

\section{Procedure}

Psychotherapists provided to their patients the access codes to the online system. These codes were previously entered by the researcher in a database that linked each patient code with its respective therapist.

After the registration, an automatic e-mail was sent asking the user to confirm its registration. Only registered patients were allowed to play the game; after playing, patients were asked to respond the online post-game questionnaire. An automatically generated e-mail was sent to the researcher and to the respective therapist informing that a particular patient finished the game and the in-game decisions that the player made. In following sessions, psychotherapists evaluated the state of the patients and if they considered it appropriate, they debriefed the game experience and its relation with the patients' problems. A brief text with suggestions on how to conduct the debriefing session was prepared and given to the therapists. The researcher arranged interviews with the therapists to evaluate the participation of each of the patients; these interviews were audio recorded. Two interviews with each therapist were conducted. The study was conducted during the year 2013.

\section{Data analysis procedures}

Patients' acceptability data was stored online and later organized in a SPSS format. Mean scores for each patient were calculated for the acceptability scale (Figure 2).

Interviews of the therapist were recorded in audio and then transcribed. These transcriptions were sent by e-mail to the respective therapists to sanction them or to make modifications according to their criteria. The revised transcriptions were incorporated to a qualitative database using the NVIVO software (version 8.0).

Interview data was analyzed using qualitative content analysis techniques. Qualitative content analysis seeks to classify the data in the form of text into categories that represent similar meanings. According to Hsieh and Shannon (2005), qualitative content analysis can be defined as a research method for the subjective interpretation of the content of text data through the systematic classification

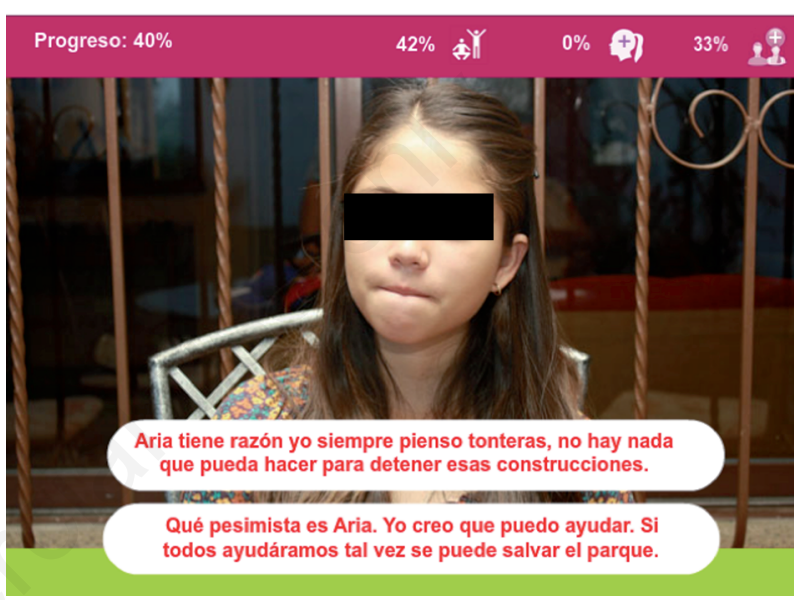

Figure 1. Screenshot of a video game scene. Aria is a friend of Maya, who criticizes her intention of supporting the social movement to stop the destruction of the park. This scene presents two options to the player. The phrase on top reads: Aria is right, I always think dumb things, there is nothing that I can do to stop those constructions. The phrase in the bottom reads: Aria is very pessimistic. I think that I can help. If everyone would help maybe the park can be saved. The bar on the top presents the progress in the game and the score for the three areas that the game explores: behavioral activation and healthy living; recognition and modification of negative cognitive bias; promotion of interpersonal skills and interpersonal problem solving.

Table 1. Acceptability scale items.

Items

I think that this game could be beneficial to me

After playing this game, I think that it could be of value to me

I think this is an important game

I think that playing this game could help me relate to other people

I would be willing to play again because it is of value to me

I think playing this game is important because it can help you think about behaviors that help you and behaviors that are harmful

I think this game is useful to learn how to relate better to other people 
process of coding and identifying themes or patterns. In inductive content analysis the categories are derived from the data.

An inductive content analysis was performed on the opinions of the therapists. Each interview was read, analytic categories were emergently created and using these categories the text was coded. The next step was to review the categories and make a descriptive summary, accounting for the commonalities but also taking note of the particularities.

\section{Results}

\section{Playtime}

The average of playtime was 11:57 minutes $(\mathrm{SD}=03: 42 \mathrm{~min}$ ). Patients could play the game as many times as they wanted. Most of the players played once, but four patients played twice.

\section{Acceptability}

Two of the fifteen patients played the game but did not answer the acceptability questionnaire, one patient (M12) played twice and she provided two responses to the acceptability scale.

Four of the patients reported acceptability mean scores values below 1 , which suggests that they estimated that the game was not beneficial for them. Five patients reported mean values between 1.5 and 2.5; these patients had favorable opinions about the benefit derived from playing the game. Five patients had mean acceptability values above 2.5 , which indicate strong opinions regard- ing the potential benefit of the game. The group acceptability mean score was $1.88(\mathrm{SD}=1.09)$.

\section{Post session psychotherapists' reports and general remarks content analysis}

The comments reported in the post-game sessions and other general remarks of the therapists were analyzed. An inductive content analysis of the transcribed interviews was conducted.

\section{Model}

One therapist said that the three areas in the video game (interpersonal relations, activity and cognitions) provided a reference, a useful model to explore with their patients. For this therapist, this model is a pertinent, concrete, psycho-educational and behavioristic treatment approach that fits well the psychotherapeutic work that can be done at her center, given the patients' problems, as well as the resource and time constraints.

\section{Therapeutic relationship}

One of the therapists mentioned that proposing to the girls to play a video game as part of the therapy contributed positively to the relationship since it was a way of connecting with their interests.

\section{Relation between the video game and patients' lives}

According to the therapists, the content of the game story or the feedback mirrored life situations, concerns or interests of the patients. Some common themes were: father-daughter relationship, student-mentor relationship,

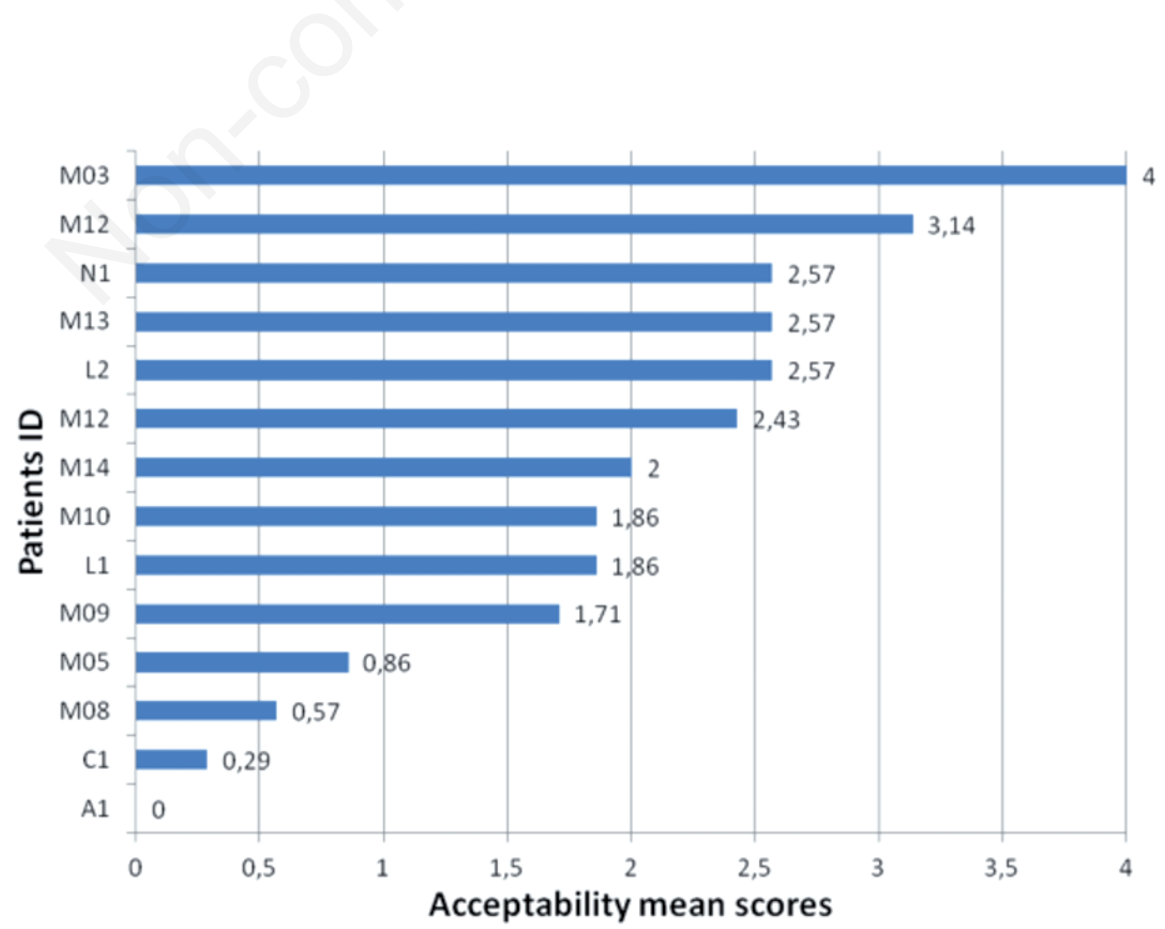

Figure 2. Patients' acceptability mean scores. 
healthy/unhealthy behaviors, social engagement and ecological sensitivity. According to the reports of the therapists, it was possible, in most of the post-game sessions, to relate elements of the game with aspects of the patients' lives. For example, one therapist reported the following exchange during a session.

Therapist: Was there something particularly interesting in the game?

Patient: When she asked help from her teacher. To look for an external and older person that motivates you to do something, that orients you, that external support is always good. I had a teacher like that, he motivated us. It was good that character appeared, it is novel and interesting.

Another therapist said that the game, by means of reflecting aspects of the patient, contributed to the externalization of the patient's emotions and, in that way, it contributed to active her. In this context, this patient revealed that she was bulimic.

In the other hand, when asked by their therapists, two of the girls were not able, on their own, to establish connections between the game and their realities. They said that the game was not related to them (even when the therapists thought the contrary) or they focused on the manifest content of the story game (the protection of nature), unaware that the situations that demanded their decisions in the video game were related with behaviors relevant to their mental health. In these cases, it was reported that the intervention of the therapist was necessary to call the attention to relevant aspects of the game. Even with these patients the video game served as a reference to introduce relevant themes or considerations for their treatment.

\section{Other qualitative opinions}

\section{Communication}

One therapist said that the video game could help to establish a line of communication with reserved or inhibited patients.

\section{Virtual world}

One of the therapists said that the project was interesting because it studies the incorporation of the increasingly present virtual world in therapy.

\section{Productive use of the web}

One of the therapists said that parents were very well disposed to allow the participation of their daughters in the research; one of the mothers said: ... well at least all the hours that she spends in front of the computer can be of some use for her.

\section{Video games for prevention}

Three of the therapists expressed that they considered that the game could be a tool for a depression prevention program.

\section{Discussion}

For four of thirteen patients the video game was not acceptable as part of their psychotherapeutic treatment. The majority of the patients reported positive acceptability rates. This indicates that most of the patients valued the video game and that they considered that they could obtain benefits from playing it, in terms of learning helpful social and mental health-related behaviors.

It is worth to mention here that for patients already addicted to video games, this ludic strategy might not be recommendable. In addition, although the story and the video game were reviewed and approved by nine psychotherapists, it was later called to the author's attention that some aspects of the story (for example the father of the protagonist being a lawyer) should be evaluated critically since those elements are extraneous in the life of many young patients. Psychotherapists should be aware of the characteristics, vulnerabilities and needs of their patients when considering incorporating video games, as well as other tools, in the treatment of a particular case.

The video game presented information in a text format so it required at least a basic reading comprehension skill. For a game like this, difficulties to read can interfere with its acceptability in the context of psychotherapy.

According to the opinions expressed by the therapists, a video game like Maya could be a useful complementary tool for psychotherapy of adolescent girls. All therapists expressed positive evaluations and they gave different reasons about why the game could be useful.

The model of the video game, based on cognitive behavioral and interpersonal theories, provides a psychotherapeutic frame that fits well to the psycho-educational and behavioristic oriented work that is conducted in a highly demanded public mental health service. Also, in such environment, it is frequent that sessions are every two weeks or even once a month, therefore an online video game could be a resource to keep the patient in a virtual extension of the therapy; as one therapist said it is like taking the therapist home or as another put it it is like and extension of the therapist.

The invitation to play a video game as part of the therapy was well received by the patients and it provided a positive element to the therapeutic relationship, insofar as, by this act, the therapist recognizes and validates an aspect that is common in adolescents' lives. Since establishing a good relationship is a challenge in adolescent psychotherapy (Coyle et al., 2005), the positive reception of a therapist's initiative is a valuable psychotherapeutic opportunity. The video game also provides an indirect, mediated line of communication that can be useful, especially, in cases or in phases of the therapy when patients are not verbally expressive. The opinions about the contribution of the video game to the therapeutic relationship and to the communication between therapist and patient support previous reported experiences (Ceranoglu, 2010). 
But it is important also to note that since the game can be perceived by the patient as an extension of the therapist, the state of the therapeutic relationship can be a factor that influence the game experience and the acceptability of the video game. For example, an oppositional attitude can negatively predispose patients when playing. This means that although the act of inviting to play could help to build the therapeutic relationship, the benefit that players obtain from playing depends, in part, on the state of the therapeutic relationship.

There is some evidence that the video game was useful to stimulate reflections about the patients' lives and that these considerations were relevant for their problems. Even though the game presented some aspects of adolescent life and problems in an indirect way, it was isomorphic enough to mirror some key aspects of reality. This was sufficient for some girls to make the connection with their lives. Other girls focused on the manifest content of the story, unaware of the procedural learning aspect of the interactive narrative.

The importance of the post-game assisted reflection, or metaplay, should be noticed. Sometimes the connection was not a self-realization of the patients; the therapist was needed to call the attention of the patients to the game situations that were relevant for their problems. In this same aspect, it is also important to note the characteristics of the game score system and the pre-defined post-game feedback, especially in cases of depressive players. For one part, these game elements must provide information in such a way that stimulate self-reflection but with the precaution of not sending messages that could easily be negatively interpreted by depressive players.

Another aspect positively evaluated by some therapists was that the incorporation of video games in therapy recognizes the virtual reality and tries to deal with it in the context of psychotherapy. The Internet, the different ways of connecting and communicating are realities that enter the space of psychotherapy especially, but not exclusively, in the cases of adolescents.

There were opinions that a video game like Maya could be a tool in online prevention programs for depression. This type of video game, in the context of a wider preventive program, could help as a first step in the emotional and behavioral activation of depressive patients and it could provide a way to stay in contact with the external world, with a therapist, especially in cases of socially withdrawn depressive people.

There are some limitations that should be noted. The opinions and reports in this article are based on a small number of patients and therapists. In this study, the information about the pertinence of the game in psychotherapy was based prevalently on therapists' reports; future research could include, for example, audio recordings of sessions in order to obtain more detailed information on how this device or a similar one affects the process of psychotherapy. Patients' opinions were collected through the acceptability questionnaire; future research could also in- clude interviews to the patients. The acceptability scale was developed specifically for this project, therefore its psychometric properties would need more study.

\section{Conclusions}

In conclusion, nine of thirteen depressive patients in this study accepted the video game and, according to their therapists, it was a useful tool in the context of their psychotherapies. This adventure video game was an innovation in the field of mental health (Ceranoglu, 2010; Kato, 2010; Wilkinson et al., 2008; Griffiths, 2003) and it shows possible courses of development and inquiry. Probably one of the most important contributions of this work is that the video game and the experiences presented provide initial evidence that future developments of video games for mental health are worthwhile. This was a very simple game, built during the early developments of information technology that it recognizes a future in which interactive devices and artificial intelligence will offer vast possibilities for education and mental health.

\section{References}

Amanita Design (2007). The Quest for the Rest [Video game]. Czech Republic. Available from: http://amanita-design.net/ thequestfortherest/

Baranowski, T., Buday, R., Thompson, D.I., \& Baranowski, J. (2008). Playing for real: Video games and stories for healthrelated behavior change. American Journal of Preventive Medicine, 34(1), 74-82.e10. doi: 10.1016/j.amepre.2007.09.027

Batista, B., \& Cornachione, E. (2005). Learning styles influences on satisfaction and perceived learning: Analysis of and online business game. Developments in Business Simulation and Experiential Learning, 32, 22-30.

Brewin, C.R. (1996). Theoretical foundations of cognitive-behavior therapy for anxiety and depression. Annual Review of Psychology, 47, 33-57. doi: 10.1146/annurev.psych.47.1.33

Brezinka, V. (2008). Treasure Hunt: a serious game to support psychotherapeutic treatment of children. Studies in Health Tecnology and Informatics, 136, 71-76.

Campbell, J. (1973). The hero with a thousand faces. Princeton, NJ: Princeton University Press.

Campbell, J. (1991). The power of myth. New York: Anchor Books.

Carter, S.L. (2007). Review of recent treatment acceptability research. Education and Training in Developmental Disabilities, 42(3), 301-316.

Ceranoglu, T.A. (2010). Video games in psychotherapy. Review of General Psychology, 14(2), 141-146. doi: 10.1037/a0019439

Coyle, D., Doherthy, G., \& Sharry, J. (2009). An evaluation of a solution-focused computer game in adolescent interventions. Clinical Child Psychology and Psychiatry 14(3), 345360. doi: 10.1177/1359104508100884.

Coyle, D., Matthews, M., Sharry, J., Nisbet, A., Doherty, G. (2005). Personal investigator: A therapeutic 3D game for adolescent psychotherapy. Journal of Interactive Technology \& Smart Education, 2(2), 73-88. doi: 10.1108/1741565058 0000034 
Davidson, K., Rieckmann, N., \& Lespérance, F. (2004). Psychological theories of depression: Potential application for the prevention of acute coronary syndrome recurrence. Psychosomatic Medicine, 66(2), 165-173. doi: 10.1097/01.psy. 0000116716.19848 .65

De Grove, F., Van Looy, J., \& Courtois, C. (2010). Towards a serious game experience model: Validation, extension and adaptation of the GEQ for use in an educational context. Playability and player experience - Proceedings of the Fun and Games 2010 Workshop 10, 47-62. Available from: https://gurworkshops.wordpress.com/2010/

Delmas, D., Champagnat, R., \& Augeraud, M. (2007). Bringing interactivity into Campbell's hero's journey. In Cavazza M., \& Donikian S. (Eds.), Lecture notes in computer science: Vol. 4871. Using virtual reality technologies for storytelling [Digital version] (pp. 187-195). Springer. doi: 10.1007/9783-540-77039-8_17

Dickey, M. (2006). Game design narrative for learning: Appropriating adventure game design narrative devices and techniques for the design of interactive learning environments. Educational Technology Research and Development 54(3), 245-263. doi: 10.1007/s11423-006-8806-y

Fernández-Vara, C., \& Osterweil, S. (2010). The key to adventure games design: Insight and sense-making. Meaningful Play, Conference Proceedings. Available from: meaningfulplay.msu.edu/proceedings2010/mp2010_paper_25.pdf

Gladstone, T., \& Beardslee, W. (2009). The prevention of depression in children and adolescents: A review. The Canadian Journal of Psychiatry, 54(4), 212-221.

Griffiths, M. (2003). The therapeutic use of videogames in childhood and adolescence. Clinical Child Psychology and Psychiatry, 8(4), 547-554. doi: 10.1177/13591045030084012

Hollon, S., Thase, M., \& Markowitz, J. (2002). Treatment and prevention of depression. Psychological Science in the Public Interest, 3(2), 39-77. doi: 10.1111/1529-1006.00008

Horowitz, J., \& Garber, J. (2006). The prevention of depressive symptoms in children and adolescents: A meta-analytic review. Journal of Consulting and Clinical Psychology, 74(3), 401-415. doi: 10.1037/0022-006X.74.3.401

Hsieh, H.F., \& Shannon, S.E. (2005). Three approaches to qualitative content analysis. Qualitative Health Research, 15(9), 1277-1288. doi.: 10.1177/1049732305276687

Ip, B. (2010). Narrative structures in computer and video games: Part 1: Context, definitions, and initial findings. Games and Cultures, 6(2), 103-134. doi: 10.1177/1555412010364982

Jung, C. (1993). Símbolos de transformación [Symbols of transformations]. Barcelona: Ediciones Paidos.

Kato, P.M. (2010). Video games in health care: Closing the gap. Review of General Psychology, 14(2), 113-121. doi: 10.1037/a0019441

Kazdin, A. (1980). Acceptability of alternative treatments for deviant child behavior. Journal of Applied Behavior Analysis, 13(2), 259-273. doi: 10.1901/jaba.1980.13-259

McFarlane, A., Sparrowhawk, A., \& Heald, Y. (2002). Report on the educational use of games. Available from: www.teem. org.uk

Moras, K. (2006). Twenty-five years of psychological treatment research on unipolar depression in adult outpatients: Introduction to the special section. Psychotherapy Research, 16(5), 519-525. doi: 10.1080/10503300600919398

Newman, M. (1996). Psychiatric disorder in a birth cohort of young adults: Prevalence, comorbidity, clinical significance, and new case incidence from ages 11 to 21. Journal of Consulting and Clinical Psychology, 64(3), 552-562. doi: 10.1037/0022-006X.64.3.552

Rebetez, C., \& Betrancourt, M. (2007). Video game research in cognitive and educational sciences. Cognition, Brain and Behavior, 11(1), 131-142.

Ritter, C., Göbel, S., \& Steinmetz, R. (2010). A critical reflection on the use of storytelling and game technology to motivate children to deal with socio-critical issues. Workshop Interactive Storytelling for Children. Available from: hoc.elet.polimi.it/idc/2010/assets/doc/Ritter-et.al.pdf

Roth, A., \& Fonagy, P. (2005). Depression. In Roth A., \& Fonagy P. (Eds.), What works for whom? (pp. 66-149). New York: The Guilford Press.

Rovai, A. (2009). Development of an instrument to measure perceived cognitive, affective, and psychomotor learning in traditional and virtual classroom higher education settings. The Internet and Higher Education, 12(1), 7-13. doi: 10.1016/ j.iheduc.2008.10.002

Seeley, J., Stice, E., \& Rohde, P. (2009). Screening for depression prevention: Identifying adolescent girls at high risk for future depression. Journal of Abnormal Psychology, 118(1), 161-170. doi: 10.1037/a0014741

Squire, K. (2008). Video-game literacy. A literacy of expertise. In Coiro J., Knobel M., Lankshear C., \& Leu D. (Eds.) Handbook of research on new media literacies (pp. 635670). New York: MacMillan.

Vitiello, B. (2009). Treatment of adolescent depression: What we have come to know. Depression and Anxiety, 26(5), 393395. doi: $10.1002 /$ da. 20572

Vogler, C. (2007). The writer's journey: Mythic structures for storytellers and screenwriters. London: Boxtree.

Wilkinson, N., Ang, R., \& Goh, D. (2008). Online video game therapy for mental health concerns: A review. International Journal of Social Psychiatry, 54(4), 370-382. doi: 10.1177/ 0020764008091659

Wolf, M. (1978). Social validity: The case for subjective measurement or how applied behavior analysis is finding its heart. Journal of Applied Behavior Analysis, 11(2), 203-214. doi: 10.1901/jaba.1978.11-203 